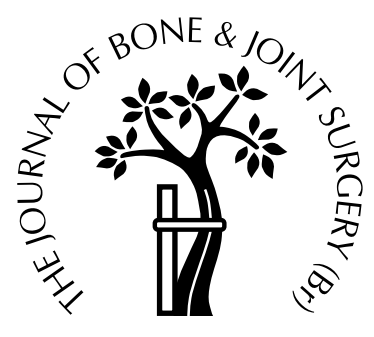

Review article

\title{
GRAFT SELECTION IN RECONSTRUCTION OF THE
} ANTERIOR CRUCIATE LIGAMENT

\author{
R. J. Bartlett, M. G. Clatworthy, T. N. V. Nguyen \\ From Melbourne, Australia
}

Only 20 years ago reconstruction of the anterior cruciate ligament (ACL) involved an open intra-articular operation in which the graft was placed in a position where it was not anatomical and which involved opening both the medial and lateral capsules. There was a long scar and considerable analgesia was required after the operation. The patient remained in hospital for ten days and in a cast for six weeks. Now, a less invasive procedure allows positioning of the graft to give a full range of movement without impingement and with restoration of stability.

Which type of graft is now used? A poll of members of the Australian Knee Society in 2000 revealed that all used autograft only, with $58 \%$ employing both patellar tendon and hamstring grafts in certain circumstances; the remainder were evenly divided in their preference for 'only' patellar tendon or 'only' hamstring. 'Members of the ACL Study Group showed a different perspective, with $73 \%$ choosing the patellar tendon, $23 \%$ the hamstrings and $4 \%$ 'others', such as allografts. This had not changed from a previous survey two years earlier. ${ }^{2}$ Another survey of orthopaedic surgeons caring for American football teams in the major leagues showed that all but one chose autologous patellar tendon grafts.

This article evaluates the available choices of graft and examines their advantages and disadvantages, the clinical outcomes, morbidity at the donor site, biomechanical characteristics and healing. We consider whether certain grafts are more suitable in particular cases and speculate as to the future directions of surgery of the ACL considering tissue engineering, growth factors and gene therapy.

R. John Bartlett, MB BS, FRACS, Honorary Orthopaedic Consultant Austin and Repatriation Medical Centre, Suite 1, 210 Burgundy Street, Heidelberg 3084, Melbourne, Australia.

M. G. Clatworthy, MB BS, FRACS, Orthopaedic Consultant Auckland Bone and Joint Surgery, Private Bag 28912, Remuera, Auckland, New Zealand.

T. N. V. Nguyen, MB BS, Orthopaedic Registrar, Melbourne 1 Earl Street, KEW, Victoria, 3101, Melbourne, Australia.

Correspondence should be sent to Mr R. John Bartlett.

(C)2001 British Editorial Society of Bone and Joint Surgery 0301-620X/01/512308 \$2.00

J Bone Joint Surg [Br] 2001;83-B:625-34.

\section{Choices of graft}

\section{Autografts}

Biomechanical comparison. Wilson et $\mathrm{al}^{4}$ studied the biomechanical properties of 15 matched pairs of centralthird bone-patellar tendon-bone and double-looped semitendinosus/gracilis grafts harvested from 15 cadavers with a mean age of 40 years. The mean load to failure for the patellar tendon grafts was $1784 \pm 580 \mathrm{~N}$, compared with $2422 \pm 538 \mathrm{~N}$ for the hamstring tendons. There was no significant difference in stiffness between the two. The elastic modulus was $225 \mathrm{MPa}$ for the patellar tendon and $145 \mathrm{MPa}$ for the hamstring tendon grafts. The mean crosssectional area of the hamstring grafts was $57 \mathrm{~mm}^{2}$ compared with $45 \mathrm{~mm}^{2}$ for those from the patellar tendon.

Simonian et $\mathrm{al}^{5}$ cyclically tested grafts $10 \mathrm{~mm}$ wide from the central-third patellar tendon and from doubled semitendinosus and gracilis tendons obtained from six fresh frozen cadavers for 1000 cycles from 0 to $300 \mathrm{~N}$. They found no significant differences in the strain, stress or modulus between the two.

Harris et $\mathrm{al}^{6}$ examined the strength of the central quadriceps tendon as compared with the central-third of the patellar tendon in 15 preserved and six fresh frozen specimens. The quadriceps tendon was found to be 1.8 times thicker and 1.36 times stronger than a patellar tendon graft of comparable width. Staubli et $\mathrm{al}^{7}$ analysed the mechanical properties of $10 \mathrm{~mm}$ wide, full-thickness central parts of the quadriceps and patellar tendons from paired knees of eight male donors with a mean age of 24.9 years. The specimens were tested unconditioned and after cyclic preconditioning. The mean cross-sectional area of the quadriceps tendons was significantly larger than that of the patellar tendons $\left(64.6 \pm 8.4 \mathrm{~mm}^{2}\right.$ and $36.8 \pm 5.7 \mathrm{~mm}^{2}$, respectively). However, the mean ultimate values for tensile stress of the patellar tendons were significantly larger than those for the quadriceps tendons $\left(53.4 \pm 7.2 \mathrm{~N} / \mathrm{mm}^{2}\right.$ and $33.6 \pm$ $8.1 \mathrm{Nmm}^{2}$, respectively).

There is a wide variation in the values reported in the literature but those commonly quoted are listed in Table I. Morbidity of the donor site

Pain. A long-term follow-up of ACL reconstructions for a minimum of seven years ${ }^{8}$ showed that patients scored a mean of 79 points on a pain scale, with 100 equalling no 
Table I. Accepted values for ultimate tensile load and stiffness

\begin{tabular}{lll}
\hline & Ultimate tensile load (N) & Stiffness $(\mathbf{N} / \mathbf{m m})$ \\
\hline Native ACL $^{139}$ & 2160 & 242 \\
Doubled semitendinosus/gracilis $^{140}$ & 4140 & 807 \\
Bone-patellar tendon-bone (10 mm) $^{141}$ & 2977 & 455 \\
Quadriceps (10 mm) $^{7}$ & 2352 & 326 \\
Bone-patellar tendon-bone allograft fresh frozen $^{102}$ & 2552 & 633 \\
Bone-patellar tendon-bone allograft after 3 Mrad irradiation $^{102}$ & 1990 & 531 \\
\hline
\end{tabular}

pain. The grade of patient satisfaction correlated more highly with the absence of pain than with any other variable assessed.

When questioned closely, patients will often admit to pain. In comparative series anterior knee pain was experienced in seven of 38 patients with a semitendinosus/gracilis graft compared with 23 of 35 with a patellar tendon graft, one year after operation. ${ }^{9}$ In those with a hamstring graft the pain was mild in five and moderate in two whereas with the patellar tendon procedure 19 had mild and four moderate pain. Anterior knee pain is commonly attributed to the use of the patellar tendon. The reported incidence of retropatellar pain is variable, ranging from $4 \%$ to $40 \%{ }^{10-14}$

D'Agata et $\mathrm{al}^{15}$ studied the area of patellofemoral contact and pressure after harvesting of the central-third of the patellar tendon in five cadaver knees. By using pressuresensitive film and isometric quadriceps forces, the contact area and pressure were measured in each specimen in the normal knee, after removal of the graft and after closure of the tendon defect. Neither harvesting the central $10 \mathrm{~mm}$ of the patellar tendon nor closing the gap significantly altered the area of patellofemoral contact or the pressure. However, Friis et $\mathrm{al}^{16}$ using thermoelastic analysis showed that stresses on the anterior surface of the patella were significantly greater when the bone block had been excised than in the intact patella. Following hamstring grafting patients may experience symptoms at the donor site ${ }^{9}$ which may be of concern in football and in sprinting sports.

The size of the operation scar has usually been considered to be of cosmetic relevance only. However, patients are concerned by loss of sensation and Kartus et $\mathrm{al}^{12}$ showed that this correlated with difficulty in kneeling and walking.

Power. There is a demonstrable loss of power in the associated muscles after repair of the ACL. A follow-up at seven years of patients who had received a patellar tendon graft showed persisting loss of both concentric and eccentric quadriceps power. This group of 30 patients also had some hamstring weakness. ${ }^{8}$ The measurements were obtained using an isokinetic dynamometer at $60^{\circ}$ per second, which is a comfortable speed for testing eccentric strength. Concentric quadriceps power was $85.8 \%$ of normal, eccentric quadriceps power $92.8 \%$ and concentric hamstring power $94.9 \%$. Only concentric quadriceps power showed some correlation with the grade of patient satisfaction.
The effect of using the central-third of the patellar tendon on the strength of the quadriceps muscle has been a cause for debate. Studies which evaluated knees after operation consistently showed significant deficits in quadriceps strength. ${ }^{14,17,18}$ The smallest loss occurred in patients ${ }^{19}$ who had an aggressive postoperative programme of rehabilitation. The quadriceps deficit was attributed to harvest of the graft. ${ }^{14}$

In order to determine whether the quadriceps deficit is due to the knee injury itself or to harvest of the graft, the strength of the quadriceps has been compared after reconstruction of the patellar tendon by allograft and autograft. Other studies ${ }^{20,21}$ have shown relative quadriceps weakness with no difference between allograft and autograft. No difference in quadriceps strength was noted when hamstring grafts were compared with those of the patellar tendon. ${ }^{22}$ Further insight is gained when knees which have been treated conservatively after rupture of the ACL are evaluated. Wojtys and Huston ${ }^{23}$ compared 40 normal knees with 100 with cruciate deficiency; $21.4 \%$ of males and $33.5 \%$ of females had a quadriceps deficit. Lorentzon et $\mathrm{al}^{24}$ examined 18 patients with chronic damage to the ACL and found a deficit of $13 \%$ to $29 \%$ in the injured limb.

Ten patients were studied in whom the patellar tendon graft was taken from the normal knee for reconstruction of the opposite unstable joint. ${ }^{25}$ Before operation the unstable knee had the weaker quadriceps. Both knees took 15 months to recover but the unstable knee remained the weaker, despite harvest of the graft from the normal knee. It is interesting to speculate on this persisting weakness. Clearly, normal function was not restored. This may be due to damage to the articular cartilage or meniscus or, as suggested by Corrigan, Cashman and Brady, ${ }^{26}$ there may be some proprioceptive benefit from hamstring dominance in the ACL-deficient knee.

A prospective comparison was made between 38 patients undergoing reconstruction of the ACL with a semitendinosus/gracilis graft and 35 with a graft of one-third of the patellar tendon. At one year both hamstring and patellar tendon grafts showed an approximate loss of $10 \%$ of quadriceps power compared with the normal opposite knee. ${ }^{9}$ The semitendinosus/gracilis graft showed a loss of $10 \%$ of hamstring power whereas the patellar tendon group showed a slight increase. Hamstring power may improve with time. In a series of 31 patients in an older age group assessed at a 
mean of four years after operation, ten had a patellar tendon graft and in 21 the hamstrings were used. ${ }^{27}$ There was no difference between the groups with each having $102 \%$ of hamstring power compared with the contralateral leg. Both had $95 \%$ of power of extension.

Other studies have compared muscle strength with a patellar tendon or hamstring graft. Carter and Edinger ${ }^{28}$ evaluated 106 patients at six months and showed no statistically significant difference in the strength of isokinetic flexion and extension. Similarly, Aglietti et al ${ }^{29}$ prospectively studied 60 patients at a mean of 28 months and found no significant difference in peak torque in extension or flexion. Hiemstra et $\mathrm{al}^{30}$ found that after one year, deficits in the strength of knee flexion of up to $50 \%$ were observed only in the hamstring tendon group with the greatest loss occurring beyond $60^{\circ}$. Similarly, deficits in the strength of extension of up to $50 \%$ between $60^{\circ}$ and $95^{\circ}$ were observed only in the patellar tendon group.

Length of the patellar tendon. Shaffer and Tibone ${ }^{31}$ in a prospective study of patients with arthroscopic reconstruction of the ACL using the middle third of the patellar tendon with the defect closed, found a mean of $2.28 \%$ of shortening of the tendon. Muellner et $\mathrm{al}^{13}$ found no correlation of anterior knee pain with shortening of the patellar tendon.

Other studies have described shortening of the patellar tendon after harvest of the graft. ${ }^{10,13,32}$

Fracture of the patella. Christen and $\mathrm{Jacob}^{33}$ reported six longitudinal fractures of the patella at the time of harvest. We have also noted this extremely rare complication due to errors in surgical technique when using osteotomes or with unnecessarily deep saw cuts. There may be a predisposition to late fracture. However, this appears to be very slight and has not prevented orthopaedic surgeons from choosing the patellar tendon as the most popular graft in contact football. ${ }^{3}$

Morphology of the donor tendon after harvest. After harvest of the middle third of the patellar tendon, extensive scar formation has been noted with poor orientation of the collagen fibres. ${ }^{34,35}$ In the $\operatorname{dog}^{36}$ the donor tendon after six months showed failure on loading of $60 \%$ of the control group; stiffness was reduced to $70 \%$ and modulus to $33 \%$. The results of closing or leaving the tendon defect open are comparable in terms of pain, the radiographic appearance and isokinetic testing. ${ }^{37-39}$

Other studies with MRI ${ }^{40,41}$ have shown reconstitution of the semitendinosus and gracilis tendons, often with a more proximal attachment. They did not show hypertrophy of the semimembranosus or biceps femoris muscles.

Healing of the graft to bone. The ligament-bone interface is a highly specialised site designed to diminish stress concentration at the interface of the soft and hard tissue. The insertion may be direct or indirect. Direct insertion shows four distinct zones: ligament, unmineralised fibrocartilage, mineralised fibrocartilage and bone. The femoral origin of the ACL is a direct insertion. Indirect insertions contain collagen fibres which blend with periosteal collagen fibres, which in turn are anchored to the adjacent bone without a fibrocartilage layer. Indirect insertions contain Sharpey's fibres, which are collagen fibres that are continuous from ligament to bone. An example is the insertion of the medial collateral ligament into the tibia. Direct insertions are typically associated with long tendons inserting into small areas of bone, while indirect insertions are usually short tendons inserting into a large area.

It is widely believed that healing of the graft in the bone tunnel is faster with a patellar tendon bone block construct than with a free tendon.

Patellar tendon. In a study in rabbits Schiavone et al ${ }^{42}$ described incorporation of the bone block as early as 16 weeks, with re-establishment of the normal four-zone insertion by six to nine months. Yoshiya et $\mathrm{al}^{43}$ has demonstrated complete healing of the bone block at 12 weeks in adult dogs.

Hamstring grafts. Healing at the tendon bone tunnel interface has been evaluated in animal studies. ${ }^{44,45}$ Formation of an indirect tendon insertion by adherence of the tendon to the tunnel wall with Sharpey's fibres was observed by six weeks. One animal study of the pull-out strength of tendon healing in the bone tunnel showed that the graft did not fail by avulsion from the tunnel after 12 weeks. ${ }^{45}$ A biopsy ${ }^{46}$ of two patients who underwent revision ACL reconstruction after early rupture of a hamstring graft showed similar findings. By contrast, Weiler, Hoffman and Bail ${ }^{47}$ have shown direct tendon healing in a sheep model using biodegradable interference screws in the zone of maximal compression of the tendon.

It has not yet been determined if it is better to leave a tendon free from fixation in a tunnel or whether it should be compressed by an interference screw.

Fate of autografts. Pathological changes occur in autografts after implantation. In a clinical study Rougraff et al ${ }^{48}$ biopsied 23 patellar tendon grafts at varying stages after reconstruction. They describe four stages of ligamentisation. The initial stage of repopulation occurs during the first two months with an increasing number of fibroblasts and active nuclear morphology by three weeks. Over the next ten months, the graft goes through a stage of rapid remodelling in which the fibroblast count increases markedly, the active nuclear morphology and neovascularity remain increased, and more areas of degeneration are present as the percentage of mature collagen decreases. The third or 'maturation' stage occurs over the next two years and is characterised by a slow decline in the nuclei and the maturation of the collagen matrix. By three years the grafts are ligamentous by all the histological criteria examined.

The histological changes of the intra-articular portion of a hamstring ACL graft up to one year in sheep have been reported by Goradia et al. ${ }^{49}$ The grafts showed relative central acellularity at four weeks, with repopulation of this region with spindle cells at eight weeks. The orientation of the collagen fibres was random at four weeks, with longitudinal reorientation peripherally. Disorganisation of 
the central area was seen at eight weeks. Directional orientation of the collagen was first identified at 12 weeks, but a uniform crimp pattern was evident only in focal areas. Such a configuration was seen in $50 \%$ at 24 weeks and $75 \%$ at 52 weeks. The authors concluded that the hamstring grafts were transformed into a histological structure similar to that of a normal ACL.

Animal and human studies ${ }^{50,51}$ have shown deficiencies in graft load to failure in the first 12 months after implantation as compared with the contralateral donor tissue and with the normal ACL. In a study ${ }^{51}$ in which the graft was compared with the same one third of the patellar tendon in the opposite normal knee, it showed 53\% load to failure at three months, $52 \%$ at six months, $81 \%$ at nine months, and $81 \%$ at 12 months.

A case report, ${ }^{50}$ eight months after reconstruction using one-third bone-patellar tendon-bone, described the linear stiffness of the graft as $90 \%$ of the normal contralateral ACL, with an ultimate load to failure $87 \%$ of normal. These findings are similar to those seen in animal studies.

Oakes $^{52}$ and Shino and Oakes ${ }^{53}$ noted a predominance of small collagen fibrils (>100 nm) on electron microscopy of ACL autografts and allografts. This was independent of the type of graft, fixation, rehabilitation or surgeon. Other studies on rabbit tendons showed a strong positive correlation between the diameter of the fibrils, the tensile modulus $(\mathrm{r}=0.74, \mathrm{p}>0.05)$ and the ultimate load $(\mathrm{r}=0.72$, $\mathrm{p}>0.05){ }^{54,55}$ Hydroxypyridinium (HP) cross-link density was low in the first six months after reconstruction, but had increased at one and three years. A significant correlation ( $r=0.75, p=0.01)$ was found between the HP density and Young's modulus. The two biological reasons for the poor long-term strength of patellar tendon autografts are probably the lack of large collagen fibrils and the cross-link density. The dominance of fibrils of small diameter (>100 nm) has been observed in long-term biopsy studies on autografts and allografts in man. ${ }^{52,53}$

Widening of the tunnel. This was first described in allografts sterilised with ethylene oxide. ${ }^{56,57}$ More recently, a high incidence of widening has been reported in hamstring grafts. ${ }^{17,58-61}$ Other studies ${ }^{58,59}$ have shown a greater incidence in hamstring grafts than with patellar tendon grafts, although a CT study ${ }^{62}$ using the latter demonstrated significant expansion of the tunnel.

Widening of the tunnel was attributed to excessive movement of the graft in the tunnel when using suspensory fixation devices. ${ }^{63}$ A recent study ${ }^{64}$ evaluated tunnel widening in 259 patients who had undergone hamstring ACL reconstruction with four different fixation devices to test this 'bungy cord effect'. The Endobutton/staples construct had significantly less widening than metal interference screws, bioabsorbable interference screws and a bone mulch screw/staples construct. This suggests that there is a significant biological component which could be attributed to a variable cytokine response to surgery ${ }^{65}$ or a reaction to synovial fluid.
Other studies have shown no correlation between tunnel widening and outcome. ${ }^{17,58,60,61}$

Driving after reconstruction of the ACL. It is important to determine the optimal time for patients to return to driving after an injury or surgery to the ACL.

In a prospective study ${ }^{66}$ of the braking reaction time before and after arthroscopic reconstruction of the ACL in 73 patients, of whom most had an autologous hamstring tendon graft, 25 normal subjects were also studied as a control group. A braking reaction test was undertaken 24 hours before surgery and every two weeks after for up to eight weeks on a computer-link automobile simulator. The braking reaction time was taken as the interval between display of a red signal and the moment at which $200 \mathrm{~N}$ of force was applied to the brake pedal by transfer of the right foot from the accelerator. It was shown that the driving reaction time of patients before surgery was comparable with that of the control group. After operation, it took six weeks for the driving reaction time of the right ACL group, but only two weeks for those who had the operation on the left side, to be equivalent to that of the control group.

In another study ${ }^{67}$ in a group of ten male patients, who had had right ACL reconstruction with autologous patellar tendon graft, the brake response time was found to match that of the 12 normal control subjects as early as four to six weeks after operation.

There appeared to be no difference irrespective of whether the graft was taken from the hamstrings or the patella.

\section{Outcomes}

Patellar tendon. In the 1930 s Palmer $^{68}$ and Campbell ${ }^{69}$ were among the first to use the patellar tendon for reconstruction of the ACL. In 1963 Jones $^{70}$ described the use of the central third of the patellar tendon which was left attached to the tibial tubercle distally, with a full-length wedge of patellar bone transferred through a drill hole in the lateral femoral condyle. A vascularised patellar tendon graft was attempted by Paulos et al, ${ }^{71}$ using the medial third of the patellar tendon and its contiguous neurovascular pedicle from the inferior medial geniculate artery.

A number of studies with a minimum follow-up of five years have been published. ${ }^{72-75}$ Using the rating of the International Knee Documentation Committee or Tegner or Lysholm scores, a satisfactory outcome was found in $78 \%$ to $90 \%$ of patients. Giving-way was eradicated in $78 \%$ to $98 \%$. The best results were found in a group of 90 patients who had normal menisci at the time of surgery. The patient rating was $90 \%$ normal or nearly normal, $98 \%$ had a grade0 pivot shift and in $97 \%$ no degenerative changes were seen radiographically. ${ }^{72}$

Some studies ${ }^{73,75}$ have correlated the timing of surgery and the state of the menisci and articular cartilage with the outcome. They showed better results if the operation was carried out early and if the menisci and articular cartilage were intact.

The advantages of a patellar tendon graft are: 1) rapid 
healing of the bone blocks within the intraosseous tunnels; 2) direct rigid fixation of the bone blocks close to the aperture; and 3) good preservation of load to failure and stiffness.

The disadvantages are predominantly related to the donor site and include: 1) anterior knee pain; 2) patellar tendinitis; 3) rupture of the patellar tendon; 4) fracture of the patella; 5) increased joint stiffness; 6) late chondromalacia; and 7) injury to the infrapatellar branch of the saphenous nerve.

Hamstrings tendon. In 1939 Macey $^{76}$ described the use of the semitendinosus tendon, based distally, for intra-articular reconstruction of the ACL. The tendon was routed through osseous tibial and femoral tunnels and sutured to the periosteum. Lindemann ${ }^{77}$, in 1950 , described the transfer of the proximally-based gracilis tendon through the posterior capsule into the intercondylar notch. The graft was fixed to the tibia in an osseous bone tunnel anterior to the insertion of the ACL. Augustine ${ }^{78}$ and Lange ${ }^{79}$ used the semitendinosus with Lindemann's technique. Four-strand hamstring grafts have since become more popular consisting of either doubled semitendinosus/gracilis ${ }^{80,81}$ or quadrupled semitendinosus tendons. ${ }^{82}$

The advantages of hamstring grafts are: 1) high load to failure and stiffness; 2) a greater cross-sectional area of tendon; 3) easier passage of the graft; 4) a small incision; 5) low postoperative morbidity; and 6) less donor site morbidity.

The disadvantages are: 1) slower tendon-to-bone healing in the tunnel; 2) the possibility of injury to the saphenous nerve; 3) weakness of the hamstring muscles after operation; and 4) widening of the tunnel.

Quadriceps tendon. The use of the quadriceps tendon as a graft for the ACL has been advocated by Staubli et al ${ }^{7}$ and Fulkerson and Langeland ${ }^{83}$ who documented the good biomechanical properties of this tendon. It is two to three times thicker than the patellar tendon and is usually harvested with a bone block from the superior pole of the patella. Chen, Chen and Shih ${ }^{84}$ described the results of arthroscopic reconstruction of the ACL using quadriceps tendon-patellar bone autograft in 12 patients. After a follow-up of 15 to 24 months, ten returned to their level of preinjury sports and ten had a normal or near normal IKDC score. However, after one year the quadriceps strength was only $80 \%$ of the normal knee in 11 patients.

The advantages of this graft are: 1) a thick tendon; 2) good biomechanical properties; and 3) decreased anterior knee pain.

The disadvantages are: 1) weakness of the quadriceps after operation; 2) an unsightly scar; and 3) graft harvest is technically more difficult.

Iliotibial tract. The use of the iliotibial tract for reconstruction of the ACL was first described by Hey Grove. ${ }^{85}$ A strip of fascia lata was detached from its insertion and directed through a tunnel in the tibia. In 1963, O'Donoghue ${ }^{86}$ described a technique in which the iliotibial tract was left attached distally and routed through tunnels drilled in the tibia and femur. He reported the results on 29 patients of whom 26 had returned to some form of sport.

Bak et al ${ }^{87}$ followed up 40 patients for between two and seven years after reconstruction of the ACL with an autograft from the iliotibial band. During this time, five patients ruptured the ACL in the contralateral knee, and one on the same side. Of the remaining 34 patients, the mean Lysholm score was 97 , the IKDC score was normal or near normal in $77 \%$, and $76 \%$ of the patients returned to the same level of activity as before injury. Complaints of the appearance of the harvest site were made by $20 \%, 8 \%$ had slight pain during activity due to lateral muscle herniation and problems with staples were common.

A graft from the iliotibial tract has satisfactory mechanical properties and results in less anterior knee pain. However, there is a long lateral operative scar, a risk of herniation of the quadriceps muscle and interference with an important lateral stabiliser of the knee.

\section{Allografts}

Animal studies have shown that allografts can be used successfully in intra-articular reconstruction of the knee. $^{88-90}$

The absence of morbidity at the donor site and the small incisions required for implantation have led to consideration of the use of allograft in reconstruction of the ACL. The most commonly used allografts are the patellar tendon and tendo Achillis, but in the past other tendons and the ACL have been used.

Several studies have compared the results of allografts with autografts in reconstruction of the ACL with no significant difference in knee laxity or outcome. ${ }^{91-94}$ The results of reconstruction with allograft patellar tendon appear to be durable. Noyes and Barber-Westin ${ }^{95}$ found no significant change in knee laxity or in the overall knee score when assessing their patients at three and seven years.

The use of allografts is dependent on an effective process of screening for viral disease. The risk of such infection has been estimated at 1:600 $000 .^{96}$ The human immunodeficiency virus can survive freezing and freeze-drying in bone. ${ }^{97}$ The techniques of harvesting, sterilisation and preservation must not damage the graft.

Deep freezing appears to be superior to freeze thawing for preservation of the allograft in that it protects biomechanical properties such as load, stiffness and the modulus of elasticity. ${ }^{9,99}$

Initially, allografts were secondarily sterilised with ethylene oxide but patients developed delayed toxic and inflammatory reactions followed by failure of the graft. ${ }^{56,57}$ Gamma irradiation is now commonly used to decrease the risk of transmission of disease but it has been shown to affect the tensile properties of the ligament. The tissue morphology is also altered since irradiation separates the collagen fascicles resulting in crimping. These harmful effects have been shown to be minimal with a dosage less than 3 Mrad and therefore 2.5 Mrad is commonly 
used. $^{100,101}$ Animal studies have shown that deep-frozen gamma-irradiated ACL allografts have the potential to attain the main biomechanical properties of the normal ACL. ${ }^{100,101}$ Another study ${ }^{102}$ has demonstrated a reduction in the ultimate tensile load of fresh-frozen bone-patellar tendon-bone allograft from $2552 \mathrm{~N}$ to $1990 \mathrm{~N}$ after irradiation of 3 Mrad with a reduction of stiffness from $633 \mathrm{~N} / \mathrm{m}$ to $531 \mathrm{~N} / \mathrm{m}$.

Studies of goat patellar-tendon autograft and allograft suggest that autografts are slightly superior ${ }^{89}$ with more rapid incorporation and slightly better stability six months after operation.

Despite the attractions of no morbidity from harvest of the graft, satisfactory properties and ready availability, the use of allografts is recommended mainly for revision surgery or when multiple grafts are required for complex instabilities.

\section{Synthetic grafts}

The use of a synthetic material for ACL reconstruction was first described in 1918 by Alwyn-Smith ${ }^{103}$ who attempted to use silk sutures as a replacement. These failed within three months. Since then numerous attempts have been made to create synthetic ligaments in order to avoid the complications associated with the use of autogenous and allogeneic tissues.

Experience with fully prosthetic grafts has been disappointing. Graft substitutes have been too abrasion-sensitive resulting in rupture and osteolysis. The results have been poor with Gore-Tex grafts, ${ }^{104-106}$ Dacron, ${ }^{107-110}$ carbon fibre ${ }^{111,112}$ and the Leeds-Keio device. ${ }^{113-115}$

Kennedy et al $^{116}$ introduced the concept of the ligament augmentation device (LAD) in 1980. This is a flat piece of $6 \mathrm{~mm}$ diamond-braided polypropylene, designed to protect the biological graft while it undergoes its phase of degeneration and weakness. Several studies have evaluated the efficacy of the LAD with either hamstring or patellar tendon grafts. ${ }^{11-119}$ None has shown superior results. Fixation of the LAD at both ends can lead to failure of the biological graft as a result of stress shielding.

\section{Collagen-based ligament grafts}

Realisation of the limitations of synthetic grafts has stimulated the development of more biologically based scaffolds. Most have collagen matrices derived from demineralised bone or collagen dispersion. They have been used alone or seeded with fibroblasts in an attempt to recreate neoligaments. ${ }^{120-122}$ The initial results have been encouraging with site-specific remodelling, bone formation in the tibial tunnel, a ligament-like transition zone and an intra-articular region with orientation of the collagen as in a ligament. However, these scaffolds are allogenic and have poor tensile strength, with limited flexibility for modification.

Xenograft, tissue-engineering grafts, growth factors and gene therapy

The early results using xenografts in animal and human studies were disappointing. Apart from showing limited vascular invasion and no ingrowth of host fibrous or osseous tissue, they also showed extreme intra-articular wear and a high incidence of severe synovitis. ${ }^{123,124}$ An animal study using the extracellular matrix derived from the mucosa of porcine small intestine as a scaffold for replacement of the ACL in the goat showed promising results. ${ }^{125}$ The most recent animal studies of xenograft rejection showed that removal of alpha-Gal epitopes from the xenograft greatly reduced the immune response and was an important first step in decreasing the immune rejection in primates. ${ }^{126}$

Tissue engineering is a multidisciplinary field which merges the technologies of cell and molecular biology, tissue culture, and the material sciences. Research is presently underway to develop biological scaffolds, which are biodegradable constructs seeded with cells. Tissue-engineered ligament grafts may be the future of ACL reconstruction. Animal studies ${ }^{127,128}$ have demonstrated the generation of neoligaments and tendons by implanting polyglycolic acid scaffolds seeded with bovine tendon fibroblasts or fibroblasts isolated from bovine ACL in nude mice models. Gross and histological examination showed tissue with great similarity to normal tendons and ligaments. Composite structures comprising bone and ligament have been developed. Ibarra et al $^{129}$ have described the generation of a bone and ligament construct by seeding two different cell types onto polyglycolic acid scaffolds in nude mice models. These studies demonstrate the potential to generate autologous ACL grafts from patients' own fibroblasts and biodegradable polymer scaffolds.

It is likely that these tissue-engineered ligaments will include growth factors, which accelerate and promote healing of soft tissue. Growth factors are specific signalling molecules which direct changes in the proliferative and migratory behaviour of cells. They may promote revascularisation of the graft and healing of the bone blocks or tendinous tissue to the bone tunnels. This should enable patients to return to work and sport more quickly. The growth factors bone morphogenic protein 13, bone morphogenic protein 7 (OP1), platelet-derived growth factor, transforming growth factor $\beta$, epidermal growth factor and basic fibroblast growth factor have been shown to enhance the healing response of ligaments. ${ }^{130-133}$ These, however, are hampered by their short half-life and novel techniques are being developed to prolong their delivery. One promising avenue is gene therapy. The required growth factor can be encoded into a denatured viral or non-viral vector, which can invade target cells allowing sustained release of these growth factors. Menetrey et $\mathrm{al}^{134}$ have established persistence of a marker gene for up to 42 days in the rabbit ACL, while another study ${ }^{135}$ has demonstrated the presence of a marker gene at the tendon bone tunnel interface in a rabbit model for 21 days.

\section{Summary}

Satisfactory and enduring clinical results can be obtained with autografts and, with some reservations regarding 
donor screening, harvesting and sterilisation, also with allografts. Some patients are better suited to specific types of graft.

Sports. Evidence of hamstring weakness in flexion after harvesting of the semitendinosus/gracilis ${ }^{30}$ suggests preference for other grafts in sports such as gymnastics and wrestling. Hamstring tears are common in football and sprinting sports, which may indicate why patellar tendon grafts are the most widely used in these activities.

Patellar tendinopathy is common in basketball and tennis leading some to suggest the avoidance of grafts involving the extensor mechanism in these activities.

Occupation. The most common site for donor site pain following harvest of a patellar tendon graft is over the tibial tubercle. Hence those, such as carpet layers and tilers, whose employment requires kneeling may prefer an alternative graft.

Technical difficulties. The less experienced surgeon may find harvest of the hamstring graft to be technically less demanding than the bone-patellar tendon-bone procedure with easier passage of the smoother graft through the bone tunnel.

Rehabilitation. If difficulties in rehabilitation are anticipated, a hamstring graft requires less supervision with less risk of complications such as the infrapatellar contracture syndrome, arthrofibrosis or persisting pain. However, more rapid incorporation with graft healing to bone is found with the bone-patellar tendon-bone preparations which therefore have more potential for accelerated rehabilitation.

Open growth plate. Animal studies have demonstrated that a drill hole left empty across the growth plate will lead to localised arrest. A drill hole filled with soft tissue will not give rise to a bone bridge and growth may continue. ${ }^{136}$ Several authors ${ }^{137,138}$ have confirmed the safety of hamstring grafts across growth plates in immediately prepubertal and pubertal children.

Hyperextension. A hyperextension injury is a common cause of traumatic failure of an ACL graft. Proprioception appears to be enhanced as a result of dominance of the hamstring relative to the quadriceps. ${ }^{26}$ In the patients with a tendency to hyperextension a patellar tendon or quadriceps tendon graft is probably preferable.

Rapid return to sport. This issue is controversial and at times seems to defy the scientific data on graft healing and pathological changes. However, in Australian Rules Football, in which a high incidence of ruptures of the ACL occurs, there have been no differences in the time of returning to first-division level when comparing hamstring and patellar tendon grafts.

There is no recommended time for return to high-risk activity. This should be when strength, stability, mobility, proprioception, confidence and technical skills have been adequately rehabilitated.

Cosmesis. Kartus et al $^{12}$ have demonstrated a correlation between the size of the scar, sensory loss and anterior knee pain. Allografts have the advantage of minimising the scar and a hamstring tendon graft probably requires a smaller exposure for harvest than other autografts.

Availability and cost. These become relative factors when considering allografts and synthetics. They may also affect the choice of device for graft fixation and hence the protocol for rehabilitation.

\section{Conclusions}

Autografts are selected by most surgeons as the appropriate substitute after rupture of the ACL with allografts having a small but loyal following. The bone-patellar tendon-bone graft has a small lead over the four-strand hamstrings replacement as the most popular autograft. It remains to be seen whether tissue engineered autologous grafts or synthetics or immunologically-treated xenografts will make a significant contribution in the future.

\section{References}

1. Feller J. Presentation at Australian Knee Society Annual Meeting, Hobart, 2000.

2. Campbell JD. The evolution and current treatment trends with anterior cruciate, posterior cruciate, and medial collateral ligament injuries. Am J Knee Surg 1998;11:128-35.

3. Bradley J. Presentation at Panther symposium. Pittsburgh, 2000.

4. Wilson TW, Zafuta MP, Zobitz M. A biomechanical analysis of matched bone-patella tendon-bone and double-looped semitendinosus and gracilis tendon grafts. Am J Sports Med 1999;27:202-7.

5. Simonian PT, Williams RJ, Deng XH, Wickiewicz TL, Warrent RF. Hamstring and patella tendon graft response to cyclical loading. Am J Sports Med 1998;11:101-5.

6. Harris NL, Smith DA, Lamoreaux L, Purnell M. Central quadriceps tendon for anterior cruciate ligament reconstruction. Part I: morphometric and biomechanical evaluation. Am J Sports Med 1997;25:23-8.

7. Staubli HU, Schatzmann L, Brunner P, Rincon L, Nolte LP. Mechanical tensile properties of the quadriceps tendon and patella ligament in young adults. Am J Sports Med 1999;27:27-34.

8. Davidson P. A long-term follow-up study of patients following anterior cruciate ligament reconstruction. Thesis MSc. Latrobe University, Melbourne, Australia, 1994.

9. Bartlett J. Presentation at ESSKA. Nice, 1998.

10. Breitfuss H, Frohlich R, Povacz $P$, Resch H, Wicker A. The tendon defect after anterior cruciate ligament reconstruction using the midthird patellar tendon: a problem for the patellofemoral joint? Knee Surg Sports Traumatol Arthrosc 1996;3:194-8.

11. Corry IS, Webb JM, Clingeleffer AJ, Pinczewski LA. Arthroscopic reconstruction of the anterior cruciate ligament: a comparison of patellar tendon autograft and four-strand hamstring tendon autografts. Am J Sports Med 1999;27:444-54.

12. Kartus J, Stener $\mathbf{S}$, Lindahl $\mathbf{S}$, et al. Factors affecting donor site morbidity after anterior cruciate ligament reconstruction using bone patellar tendon bone autografts. Knee Surg Sports Traumatol Arthrosc 1997;5:222-8.

13. Muellner T, Kaltenbrunner W, Nikolic A, et al. Shortening of the patella tendon after anterior cruciate ligament reconstruction. Arthroscopy 1998;14:592-6.

14. Rosenberg TD, Franklin JL, Baldwin GN, Nelson KA. Extensor mechanism function after patellar tendon graft harvest for anterior cruciate ligament reconstruction. Am J Sports Med 1992;20: 519-526.

15. D'Agata SD, Pearsall AW, Reider B, Draganich LF. An in vitro analysis of patellofemoral contact areas and pressures following procurement of the central one-third patellar tendon. Am J Sports Med 1993;21:212-20.

16. Friis EA, Cooke FW, McQueen DA, Henning CE. Effect of bone block removal and patella prosthesis on stress in the human patella. Am J Sports Med 1994;22:696-701. 
17. Simonian PT, Eriksson MS, Larson RV, O'Kane JW. Tunnel expansion after hamstring anterior cruciate ligament reconstruction with I-incision Endobutton femoral fixation (in process citation). Arthroscopy 2000;16:707-14.

18. Yasuda K, Ohkoshi Y, Tanabe Y, Kaneda K. Quantitative evaluation of knee instability and muscle strength after anterior cruciate ligament reconstruction using patellar and quadriceps tendon. Am J Sports Med 1992;20:471-5.

19. Shelbourne KD, Gray T. Anterior cruciate ligament reconstruction with autogenous patellar tendon graft followed by accelerated rehabilitation: a two- to nine-year follow-up. Am J Sports Med 1997;25: 786-96.

20. Lephart SM, Kocher MS, Harner CD, Fu FH. Quadriceps strength and functional capacity after anterior cruciate ligament reconstruction: patellar tendon autograft versus allograft. Am J Sports Med 1993;21:738-44.

21. Stringhan DR, Pelmas CJ, Burks RT, Newman AP, Marcus RL. Comparison of anterior cruciate ligament reconstruction using patellar tendon autograft or allograft. Arthroscopy 1996;12:414-21.

22. Marder RA, Raskind JR, Carroll M. Prospective evaluation of arthroscopically assisted anterior cruciate ligament reconstruction: patella tendon versus semitendinosus and gracilis tendons. Am J Sports Med 1991;19:478-84.

23. Wojtys EM, Huston LJ. Neuromuscular performance in normal and anterior cruciate ligament deficient lower extremities. Am J Sports Med 1994;22:89-104.

24. Lorentzon R, Elmqvist LG, Sjostrom M, Fagerlun M, Fuglmeyer AR. Thigh musculature in relation to chronic anterior cruciate ligament tear: muscle size, morphology and mechanical output before reconstruction. Am J Sports Med 1989;17:423-9.

25. Bartlett J, Morris H. Presentation at ISK. Copenhagen, 1993.

26. Corrigan JP, Cashman WF, Brady MP. Proprioception in the cruciate deficient knee. J Bone Joint Surg [Br] 1992;74-B:247-50.

27. Blyth M, Gosal H, Bartlett J, Peake W. ACL reconstruction in patients over 50. Submitted for publication, 2000.

28. Carter TR, Edinger S. Isokinetic evaluation of anterior cruciate ligament reconstruction: hamstring versus patellar tendon. Arthroscopy 1999;15:169-72.

29. Aglietti P, Buzzi R, Zaccherotti G, Biase PD, Indelicato PA. Patellar tendon versus doubled semitendinosus and gracilis tendons for anterior cruciate ligament reconstruction. Am J Sports Med 1994;22: 211-9.

30. Hiemstra LA, Webber S, MacDonald PB, Kriellaars DJ. Knee strength deficits after hamstring tendon and patellar tendon anterior cruciate ligament reconstruction. Med Sci Sports Exerc 2000; 32:1472-9.

31. Shaffer BS, Tibone JE. Patellar tendon length change after anterior cruciate ligament reconstruction using the midthird patellar tendon. Am J Sports Med 1993;21:449-55.

32. Dandy DJ, Desai SS. Patella tendon length after anterior cruciate ligament reconstruction. J Bone Joint Surg [Br] 1994;76-B:198-9.

33. Christen B, Jacob RP. Fractures associated with patella ligament grafts in cruciate ligament surgery. J Bone Joint Surg $[\mathrm{Br}]$ 1992; 74-B:617-9.

34. Alfonso VS, Lopez AS, Castro CM, Sastre ER. Healing of the patellar tendon donor defect created after central-third patellar tendon autograft harvest: a long-term histological evaluation in the lamb model. Knee Surg Sports Traumatol Arthrosc 1998;7:340-8.

35. Berg EE. Instrinsic healing of a patella tendon donor site defect after anterior cruciate ligament reconstruction. Clin Orthop 1992;278: 160-3.

36. Burks RT, Haut RC, Lancaster RL. Biomechanical and histological observations of the dog patellar tendon after removal of its central one-third. Am J Sports Med 1990;18:146-53.

37. Adriani E, Mariani PP, Maresca G, Santori N. Healing of the patellar tendon after harvesting of its mid-third for anterior cruciate ligament reconstruction and evolution of the unclosed donor site defect. Knee Surg Sport Traumatol Arthrosc 1995;3:138-43.

38. Brandsson S, Faxen E, Eriksson BI, et al. Closing patellar tendon defects after anterior cruciate ligament reconstruction: absence of any benefit. Knee Surg Sports Traumatol Arthrosc 1998;6:82-7.

39. Cerullo G, Puddu G, Gianni E, Damiani A, Pigozzi F. Anterior cruciate ligament patella tendon reconstruction: it is probably better to leave the tendon defect open! Knee Surg Sports Traumatol Arthrosc 1995;3:14-7.
40. Cross MJ, Roger G, Kujawa P, Anderson IF. Regeneration of the semitendinosus and gracilis tendons following their transection for repair of the anterior cruciate ligament. Am J Sports Med 1992; 20:221-3.

41. Erisksson K, Larsson H. Wredmark T, Hamberg P. Semitendinosus tendon regeneration after harvesting for ACL reconstruction: a prospective MRI study. Knee Surg Sports Traumatol Arthrosc 1999;7:220-5.

42. Schiavone PA, Fabbriciani C, Delcogliano A, Franzese S. Bone ligament interaction in patellar tendon reconstruction of the ACL. Knee Surg Sports Traumatol Arthrosc 1993;1:4-8.

43. Yoshiya S, Nagano M, Kurosaka M, Muratsu H, Mizuno K. Graft healing in the bone tunnel in anterior cruciate ligament reconstruction. Clin Orthop 2000:278-86.

44. Blickenstaff KR, Grana WA, Egle D. Analysis of a semitendinosus autograft in a rabbit model. Am J Sports Med 1997;25:554-9.

45. Rodeo SA, Arnoczky SP, Tozilli PA, Hidaka C, Warren RF. Tendon healing in a bone tunnel: a biomechanical and histological study in the dog. J Bone Joint Surg [Am] 1993;75-A:1795-803.

46. Pinczewski LA, Clingeleffer AJ, Otto DD, Bonar SF, Corry IS. Integration of hamstring tendon graft with bone in reconstruction of the anterior cruciate ligament. Arthroscopy 1997;13:641-3.

47. Weiler A, Hoffman RF, Bail HJ. Tendon healing in a bone tunnel: histological analysis after biodegradable interference fit fixation. Arthroscopy 1999;15:548-9.

48. Rougraff B, Shelbourne KD, Gerth PK, Warner J. Arthroscopic and histologic analysis of human patella tendon autografts used for anterior cruciate ligament reconstruction. Am J Sports Med 1993; 21:277-84

49. Goradia VK, Rochat MC, Kida M, Grana WA. Natural history of a hamstring tendon autograft used for anterior cruciate ligament reconstruction in a sheep model. Am J Sports Med 2000;28:40-6.

50. Beynnon BD, Risberg MA, Tjomsland O, et al. Evaluation of knee joint laxity and the structural properties of the anterior cruciate ligament graft in the human: a case report. Am J Sports Med 1997;25:203-6.

51. Clancy WG Jr, Narechania RG, Rosenberg TD, et al. Anterior and posterior cruciate ligament reconstruction in Rhesus monkey: a histological, microangiographic and biomechanical analysis. $J$ Bone Joint Surg [Am] 1981;63-A:1270-84.

52. Oakes BW. Collagen ultrastructure in the normal ACL and in ACL graft. In: Jackson D, et al, eds. The anterior cruciate ligament: current and future concepts. New York: Raven Press, 1993:209-17.

53. Shino K, Oakes BW. Collagen fibril populations in human anterior cruciate ligament allografts: electron microscopic analysis. Am J Sports Med 1995;23:203-9.

54. Ng GYF, Oakes BW, Deacon OW, McLean ID, Eyre D. Long term study of the biochemistry and biomechanics of anterior cruciate ligament patellar tendon autografts. J Orthop Res 1996;14:851-6.

55. Oakes BW, Singleton C, Haut R. Correlation of collagen fibril morphology and tensile modulus in the repairing and normal rabbit patella tendon. TORS, New Orleans, USA. 1998;23:24-4.

56. Jackson DW, Windler GE, Simon TM. Intra-articular reaction associated with the use of freeze-dried, ethylene oxide-sterilized bone-patella tendon-bone allografts in the reconstruction of the anterior cruciate ligament. Am J Sports Med 1990;18:1-11.

57. Roberts TS, Drez D Jr, McCarthy W, Paine R. Anterior cruciate ligament reconstruction using freeze-dried, ethylene oxide-sterilized, bone-patella tendon-bone allografts. Am J Sports Med 1991; 19:35-41.

58. Clatworthy MG, Annear P, Bulow JU, Bartlett RJ. Tunnel widening in anterior cruciate ligament reconstruction: a prospective evaluation of hamstring and patellar tendon grafts. Knee Surg Sports Traumatol Arthrosc 1999;7:138-45.

59. Insalata JC, Klatt B, Fu FH, Harner CD. Tunnel expansion following anterior cruciate ligament reconstruction: a comparison of hamstring and patellar tendon autografts. Knee Surg Sports Traumatol Arthrosc 1997;5:234-8.

60. Jansson KA, Harilainen A, Dandlin J, et al. Bone tunnel enlargement after anterior cruciate ligament reconstruction with the hamstring autograft and Endobutton fixation technique: a clinical, radiographic and magnetic resonance imaging study with 2 year follow up. Knee Surg Sports Traumatol Arthrosc 1999;7:290-5.

61. Zysk SP, Kruger A, Baur A, Veihelmann A, Refior HJ. Tripled semitendinosus anterior cruciate ligament reconstruction with Endobutton fixation: a 2-3 year follow-up study of 35 patients. Acta Orthop Scand 2000;71:381-6. 
62. Fink C, Hackl C, Hoser C, Zapp M, Benedetto KP. Bone tunnel widening following ACL reconstruction: a point of concern or scientific curiosity. ACL Study Group Rhodos, Greece, 2000.

63. Hoher J, Scheffle SU, Withrow JD, et al. Mechanical behaviour of two hamstring graft constructed for reconstruction of the anterior cruciate ligament. J Orthop Res 2000;18:456-61.

64. Clatworthy MG, Bulow JU, Pinczewski LA, et al. Tunnel widening in hamstring ACL reconstruction: a prospective clinical evaluation and radiographic evaluation of four different fixation techniques. ACL Study Group, Rhodes Greece, 2000.

65. Cameron M, Buchgraber A, Passler $\mathbf{H}$, et al. The natural history of the anterior cruciate ligament-deficient knee: changes in synovial fluid cytokines and keratan sulfate concentration. Am J Sports Med 1997;25:751-4.

66. Nguyen T, Hau R, Bartlett J. Driving reaction time before and after anterior cruciate ligament reconstruction. Knee Surg Sports Traumatol Arthrosc 2000;8:226-30.

67. Gotlin RS, Sherman AL, Sierra N, Kelly M, Scott WN. Measurement of brake response time after right anterior cruciate ligament reconstruction. Arthroscopy 2000;16:151-5.

68. Palmer I. On the injuries to the ligaments of the knee joint: a clinical study. Acta Chir Scand 1938;LXXXI, Suppl 53.

69. Campbell WC. Reconstruction of the ligaments of the knee. Am J Surg 1939;43:473-80.

70. Jones KG. Reconstruction of the anterior cruciate ligament. $J$ Bone Joint Surg [Am] 1963;45-A:925-32.

71. Paulos LE, Butler DL, Noyes FR, Grood ES. Intra-articular cruciate reconstruction. II: replacement with vascularized patellar tendon. Clin Orthop 1983;172:78-84.

72. Deehan DJ, Salman LJ, Webb VJ, Davies A, Pinczewski LA. Endoscopic reconstruction of the anterior cruciate ligament with an ipsilateral patellar tendon autograft: a prospective longitudinal fiveyear study. J Bone Joint Surg [Br] 2000;82-B:984-91.

73. Jarvela T, Nyyssonen M, Kannus P, Paakkala T, Javinen M. Bone patellar tendon bone reconstruction for the anterior cruciate ligament: a long term comparison of early and late repair. Int Orthop 1999;23:227-31.

74. Jomha NM, Pinczewski LA, Clingeleffer A, Otto DD. Arthroscopic reconstruction of the anterior cruciate ligament with patellar-tendon autograft and interference screw fixation: the results at seven years. J Bone Joint Surg [Br] 1999;81-B:775-9.

75. Shelbourne KD, Gray T. Results of anterior cruciate ligament reconstruction based on meniscus and articular cartilage status at the time of surgery. Am J Sports Med 2000;28:446-52.

76. Macey HB. A new operative procedure for repair of ruptured cruciate ligaments of the knee joint. Surg Gynecol Obstet 1939;69:108-9.

77. Lindemann K. Uber den plastischen ersatz Kreutzbander durch gestielte Sehnenverpflanzung. Z Orthop 1950;79:316.

78. Augustine RW. The unstable knee. Am J Surg 1956;92:380-8.

79. Lange M. Orthopadishe-Chirurgische Operatioslehre Zweite Auflage. Munich: Bergmann, 1962:692-700.

80. Friedman MJ. Arthroscopic semitendinosus (gracilis) reconstruction for anterior cruciate ligament deficiency. Techniques in Orthopaedics 1988;2:74-80.

81. Larson RV. Arthroscopic anterior cruciate ligament reconstruction utilizing double loop semitendinosus and gracilis tendons. Instructional Courses and Symposia. Procs 11th Annual Meeting Arthroscopy Association of North America, Boston, 1992:124-8.

82. Rosenberg TD. Technique for endoscopic method of ACL reconstruction. Technical Bulletin. Mansfield, MA: Acufex Microsurgical, 1993.

83. Fulkerson JP, Langeland $\mathbf{R}$. Technical note: an alternative cruciate graft: the central quadriceps tendon. Arthroscopy 1995;11:252-4.

84. Chen $\mathbf{C H}$, Chen WJ, Shih $\mathbf{C H}$. Arthroscopic anterior cruciate ligament reconstruction with quadriceps tendon-patella bone autograft. J Trauma 1999;46:678-82.

85. Hey Grove EW. Operation for the repair of the cruciate ligament. Lancet 1917;2:674-5.

86. O'Donoghue DH. A method for replacement of the anterior cruciate ligament of the knee: report of twenty cases. J Bone Joint Surg [Am] 1963;45-A:905-24.

87. Bak K, Jorgensen U, Ekstrand J, Scavenius M. Results of reconstruction of acute ruptures of the anterior cruciate ligament with an iliotibial band autograft. Knee Surg Sports Traumatol Arthrosc 1999;7:111-7.
88. Fromm B, Schafer B, Parsh D, Kummer W. Reconstruction of the anterior cruciate ligament with a cryopreserved ACL allograft: a microangiographic and immunohistochemical study in rabbits. Internal Orthopaedics 1996;20:378-82.

89. Jackson JC, Grood ES, Goldstein JD, et al. A comparison of patellar tendon autograft and allograft used for anterior cruciate ligament reconstruction in the goat model. Am J Sports Med 1993;21:176-85.

90. Nikolaou PK, Seaber AV, Glisson RR, Ribbeck BM, Bassett FH. Anterior cruciate ligament allograft transplantation: long-term function, histology, revascularisation and operative technique. Am J Sports Med 1986;14:348-60.

91. Kleipool AE, Zijl JA, Wilems WJ. Arthroscopic anterior cruciate ligament reconstruction with bone patellar tendon bone allograft or autograft: a prospective study with an average follow-up of 4 years. Knee Surg Sports Traumatol Arthrosc 1998;6:224-30.

92. Petersen RK, Shelton WR, Bomboy AC. Allograft versus autograft patellar tendon anterior cruciate ligament reconstruction: a 5 years follow-up. Arthroscopy 2000;17:9-13.

93. Shelton WR, Papendick L, Dukes AD. Autograft versus allograft anterior cruciate ligament reconstruction. Arthroscopy 1997;13: 446-9.

94. Victor J, Bellemans J, Witvrouw E, Govaers K, Fabry G. Grafts selection in anterior cruciate ligament reconstruction: prospective analysis of patella autografts compared with allografts. Int Orthop 1997;21:93-7.

95. Noyes FR, Barber-Westin SD. Reconstruction of the anterior cruciate ligament with human allograft: comparison of early and late results. J Bone Joint Surg [Am] 1996;78-A:524-37.

96. Buck BE, Malinin TI, Brown MD. Bone transplantation and human immunodeficiency virus: an estimated risk of acquired immunodeficiency syndrome (AIDS). Clin Orthop 1989;240:129-36.

97. Buck BE, Resnick L, Shah SM, Malinin TI. Human immunodeficiency virus cultured from bone. Clin Orthop 1990;251:249-53.

98. Jackson JC, Grood ES, Cohn BT, et al. The effect of in situ freezing on the anterior cruciate ligament: an experimental study in goat. J Bone Joint Surg [Am] 1991;73-A:201-13.

99. King G, Edward P, Brant P. Freeze thawing impairs long term healing of a rabbit medial collateral ligament autograft model. Trans Orthop Res Soc 1992;17:660.

100. Goertzen MJ, Clahsen H, Burrig KF, Schulitz. Sterilization of canine anterior cruciate allografts by gamma irradiation in argon: mechanical and neurohistological properties retained one year after transplantation (Published erratum appears in J Bone Joint Surg [Br] 1995;77-B:985. Retracted by Fulford P. J Bone Joint Surg [Br] 1997;79-B:705-6). J Bone Joint Surg [Br] 1995;77-B:205-12.

101. Smith CW, Young IS, Kearney JN. Mechanical properties of tendon: changes with sterilization and preservation. J Biomech Eng 1996;118:56-61.

102. Fideler BM, Vangsness CT, Bin LU, Orlando C, Moore T. Gamma irradiation: effect on biomechanical properties of human bone-patellar tendon-bone allografts. Am J Sports Med 1995;23:643-6.

103. Alwyn-Smith $\mathbf{S}$. The diagnosis and treatment of injuries to the cruciate ligament. Br J Surg 1918;6:176.

104. Bowyer GW, Matthews SJ. Anterior cruciate ligament reconstruction using the Gore-Tex ligament. J R Army Med Corp 1991;137: 69-75.

105. Glousman R, Shields $\mathbf{C}$, Kerlan $\mathbf{R}$, et al. Gore-Tex prosthetic ligament in anterior cruciate deficient knees. Am J Sports Med 1988;16:321-6.

106. Schepsis AA, Greenleaf J. Prosthetic materials for anterior cruciate ligament reconstruction. Orthop Rev 1990;19:984-91.

107. Andersen HN, Bruun C, Sondergard-Petersen PE. Reconstruction of chronic insufficient anterior cruciate ligament in the knee using a synthetic Dacron prosthesis: a prospective study of 57 cases. Am J Sports Med 1992;20:20-3.

108. Gillquist J, Odensten M. Reconstruction of old anterior cruciate ligament tears with a Dacron prosthesis: a prospective study. Am J Sports Med 1993;21:358-66.

109. Richmond CJ, Manseau CJ, Patz R, McConville O. Anterior cruciate ligament reconstruction using a Dacron prosthesis: a long term study. Am J Sports Med 1992;20:24-8.

110. Wredmark T, Engstrom B. Five year results of anterior cruciate ligament reconstruction with the Stryker Dacron high-strength ligament. Knee Surg Sports Traumatol Arthrosc 1993;1:71-5. 
111. Bercovy M, Goutallier D, Voisin MC, et al. Carbon-PGLA prostheses for ligament reconstruction: experimental basic and short-term results in man. Clin Orthop 1985;196:159-68.

112. King JB, Bulstrode C. Polylactate-coated fiber in extra-articular reconstruction of the unstable knee. Clin Orthop 1985;196:139-42.

113. Dandy DJ, Gray AJR. Anterior cruciate ligament reconstruction with the Leeds-Keio prosthesis plus extra-articular tenodesis: results after six years. J Bone Joint Surg [Br] 1994;76-B:193-7.

114. Marcacci M, Zaffagnini S, Visani A, et al. Arthroscopic reconstruction of the anterior cruciate ligament with Leed-Keio ligament in non-professional athletes: results after a minimum 5 years follow-up. Knee Surg Sports Traumatol Arthrosc 1996;4:9-13.

115. Prescott RJ, Ryan WG, Bisset DJ. Histopathological features of failed prosthetic Leeds-Keio anterior cruciate ligaments. J Clin Pathol 1994;47:375-6.

116. Kennedy JC, Roth JH, Mendenhall HV, Sanford JB. Intraarticular replacement on the anterior cruciate deficient knee. Am J Sports Med 1980;8:1-8.

117. Grontvedt T, Engebretsen L, Bredland T. Arthroscopic reconstruction of the anterior cruciate ligament reconstruction using bone patellar tendon bone grafts with and without augmentation: a prospective, randomised study. J Bone Joint Surg [Br] 1996;78-B:817-22.

118. Santi MD, Richardson AB. The ligament augmentation device in hamstring grafts for reconstruction of the anterior cruciate ligament. Am J Sports Med 1994;22:524-30.

119. Siegel MG, Barber-Westin SD. Arthroscopic assisted outpatient anterior cruciate ligament reconstruction using the semitendinosus and gracilis tendons. Arthroscopy 1998;14:268-77.

120. Bellincampi LD, Closkey RF, Prasad R, Zawadsky JP, Dunn MG. Viability of fibroblast-seeded ligament analogs after autogenous implantation. J Orthop Res 1998;16:414-20.

121. Dunn MG, Liesch JB, Tiku ML, Zawadsky JP. Development of fibroblast-seeded ligament analogs for ACL reconstruction. J Biomed Mater Res 1995;29:1363-71.

122. Jackson DW, Simon TM, Lowery W, Gendler E. Biologic remodelling after anterior cruciate ligament reconstruction using a collagen matrix derived from demineralized bone. Am J Sports Med 1996;24:405-14.

123. Berry JL, Berg WS, Stahurski TM, et al. Evaluation of dacroncovered and plain bovine xenografts as replacement for the anterior cruciate ligament. Clin Orthop 1988;236:270-8.

124. Van Steensel CJ, Schreuder O, Van Den Bosch BF, et al. Failure of anterior cruciate ligament reconstruction using tendon xenograft. J Bone Joint Surg [Am] 1987;69-A:860-4.

125. Badylak S, Arnoczky S, Plouhar P, et al. Naturally occurring extracellular matrix as a scaffold for musculoskeletal repair. Clin Orthop 367 Suppl:333-43.
126. Stone KR, Ayala G, Goldstein J, et al. Porcine cartilage transplants in the cynomolgus monkey: III transplantation of alpha-Galactosidase-treated porcine cartilage. Transplantation 1998;65: 1577-83.

127. Cao Y, Vacanti JP, Ma X, et al. Generation of neo-tendon using synthetic polymers seeded with tenocytes. Transplantation Proceedings 1994;26:3390-1.

128. Ibarra C, Cao Y, Vacanti JP, Kim TH, Vacanti CA. Tissue engineering ligaments. Surgical Forum 1996;47:612-5.

129. Ibarra C, Cao Y, Vacanti JP, Kim TH, Vacanti CA. Tissue engineered bone-ligament-bone structure: potential new grafts for knee ligament reconstruction. SICOT 20th World Congress, Amsterdam, 1996.

130. Evans CH. Cytokines and the role they play in the healing of ligaments and tendons. Sports Med 1999;28:71-6.

131. Hildebrand KA, Woo SL, Smith DW, et al. The effects of plateletderived growth factor-BB on healing of the rabbit medial collateral ligament: an in vivo study. Am J Sports Med 1998;26:546-54.

132. Lee J, Green MH, Amiel D. Synergistic effect of growth factors on cell outgrowth from explants of rabbit anterior cruciate and medial collateral ligament. J Orthop Res 1995;13:435-41.

133. Woo SL, Hildebrand K, Watanabe N, et al. Tissue engineering of ligament and tendon healing. Clin Orthop 1999:312-23.

134. Menetrey J, Kasemkijwattana C, Day CS, et al. Direct fibroblast and myoblast mediated gene transfer to the anterior cruciate ligament. Tissue Eng 1999;5:435-42.

135. Clatworthy MG, Menetrey J, Lattermann C, Huard J, Fu F. The role of gene therapy at the tendon-bone tunnel interface in ACL reconstruction. World Congress on Orthopaedic Sports Trauma, Gold Coast, Australia, 2000.

136. Stadelmaier DM, Arnoczky SP, Dodds J, Ross H. The effects of drilling and soft tissue grafting across open growth plates: a histologic study. Am J Sports Med 1995;23:431-5.

137. Lo IK, Bell DM, Fowler PJ. Anterior cruciate ligament injuries in the skeletal immature patient. Instr Course Lect 1998;47:351-9.

138. Lo IK, Kerkley A, Fowler PJ, Miniaci A. The outcome of operatively treated anterior cruciate ligament disruption in the skeletally immature child. Arthroscopy 1997;13:627-34.

139. Woo SL, Hollis JM, Adam DJ, Lyon RM, Takai S. Tensile properties of the human femur-anterior cruciate ligament-tibia complex. The effect of specimen age and orientation. Am J Sports Med 1991;19:217-25.

140. Hamner DL, Brown CH Jr, Steiner ME, Hecker AT, Hayes WC. Hamstring tendon grafts for reconstruction of the anterior cruciate ligament: biomechanical evaluation of the use of multiple strands and tensioning techniques. J Bone Joint Surg [Am] 1999;81-A:549-57.

141. Cooper DE, Deng XH, Burstein AL, Warren RF. The strength of the central third patellar tendon graft. Am J Sports Med 1993; 21:818-23. 